\title{
EFFECT OF SPRAY DRYING PROCESS PARAMETERS ON DIFFERENT PROPERTIES OF ACID LIME JUICE POWDER
}

\author{
V.S. SONONE ${ }^{1}$, P. A. UNDE ${ }^{2} \&$ D. A. PAWAR \\ ${ }^{1}$ Ph.D. Scholar, Department of Agricultural Process Engineering, MPKV, Rahuri, India \\ ${ }^{2}$ Ex-Professor and Head, Department of Agricultural Process Engineering, MPKV, Rahuri, India \\ ${ }^{3}$ Scientist, Agro-Produce Processing Division, ICAR-CIAE, Bhopal, India
}

ABSTRACT
Spray drying parameters were the most important factors which influence the physico-chemical properties of
powders. The levels of independent variables selected for the present experimentations were 140,150 and $160^{\circ} \mathrm{C}$ inlet
air temperature, $75,87.5$ and $100 \mathrm{ml} / \mathrm{h}$ feed flow rate and 14,16 and 18 percent concentrations of carrier agents
(maltodextrin, Arabic gum and blend of maltodextrin and Arabic gum) on the basis of preliminary trials conducted.
The effect of these independent variables on the different properties such as moisture content, powder recovery, water
solubility index and vitamin C content of acid lime juice powder was determined. The maximum vitamin C content
was observed in the powder prepared using maltodextrin. The process parameters for retention of maximum vitamin C
(368.584 mg/100g) were inlet air temperature of $150^{\circ} \mathrm{C}$, concentration of maltodextrin of 16 percent and flow rate of
87.5 mL/h. RTS prepared from powder using maltodextrin. At these process conditions, moisture content, powder
recovery and water solubility index obtained were 4.098 per cent (d.b.), 16.893 per cent and 95.530 per cent,
respectively.
KEYWORDS: Powder Prepared using Maltodextrin, Process Conditions, Moisture Content, Powder Recovery and
Water Solubility Index Obtained, Rapidly Increasing Demand Both in the Domestic \& The International Market

Received: Sep 01, 2017; Accepted: Sep 18, 2017; Published: Sep 25, 2017; Paper Id.: IJASROCT201737

\section{INTRODUCTION}

Spray drying is one of the techniques used extensively in food industries and it is used under optimal processing conditions to obtain powders. Commonly, fruits are dehydrated in order to be preserved, in which moisture must be removed in a way that has the least influence on the organoleptic qualities of the product (Davoodi et al., 2007). Indeed, the health-promoting capacity of fruits depends strictly on the processing of such foods (Hunter and Fletcher, 2002). The processed fruit quality is especially important, because high fruit consumption is encouraged throughout the country for health considerations. Therefore, dehydrated fruit is under rapidly increasing demand both in the domestic and the international market and is being used largely for the preparation of nutraceutical products or convenience food. Fruit can be dehydrated by various methods and the quality of the product depends on different parameters (Mrkic et al., 2006). Fruit juice powders have many benefits and economic potentials over their liquid counterparts such as reduced volume or weight, reduced packaging, easier handling and transportation and much longer shelf life (Fazaeli et al., 2012).

Spray-drying is a common process to obtain dry powders with low moisture content from liquid products as solutions, emulsions or suspensions (Peighambardoust et al., 2011). Several advantages are recognized for this 
technique such as its low cost, high reproducibility and applicability to thermolabile materials due to the short drying time. Additionally, it is easy to operate and scale-up very fast, since the particles are produced while they are dried (Burgain et al., 2011 and Silva et al., 2011). Spray drying is used in the wide range of products in food industries to produce dry powder and agglomerates. Economic considerations of this method include hygienic conditions during processing, operational costs and short contact time (Sagar and Kumar, 2010 and Yousefi et al., 2011). Post-harvest processing of acid lime juice in the form of powder determines the effective utilization of productivity and quality of end products which ultimately lead towards the consumption and acceptance of the products. The acid lime juice powder is promoted for preparation of different health food product such as RTS premix in the world market. These numerous health benefits and huge production provide a solid basis for the development and utilization of acid lime juice as pharmaceutical, cosmetic and dietary supplement. Therefore, present investigations were undertaken to describe the effect of spray drying process parameters on different properties of fruit juice powders.

\section{MATERIALS AND METHODS}

Well matured, healthy acid lime fruits (Citrus aurantifolia Swingle) of uniform size and colour were obtained from the field of Citrus Fruits Crops, Department of Horticulture, M.P.K.V., Rahuri. Fruits were thoroughly washed with tap water to remove surface dirt and microbial flora if any, and wiped with clean muslin cloth. Juice from weighing fruit was extracted with the help of juice extractor or squeezer. The resultant juice was filtered through muslin cloth and then was to spray drying. The process flow chart for preparation of acid lime juice powder is given in Figure 1. The spray dried powder was then analyzed for different properties. Moisture content and vitamin $\mathrm{C}$ content of powder were determined by standard oven method as described by Ranganna (1986) and The powder recovery was calculated as the ratio of the weight

of the powder and weight of the feed and water solubility index of the powder was determined as per the procedure described by Cano-cacao et al. (2005) and Sarabandi et al. (2014). 


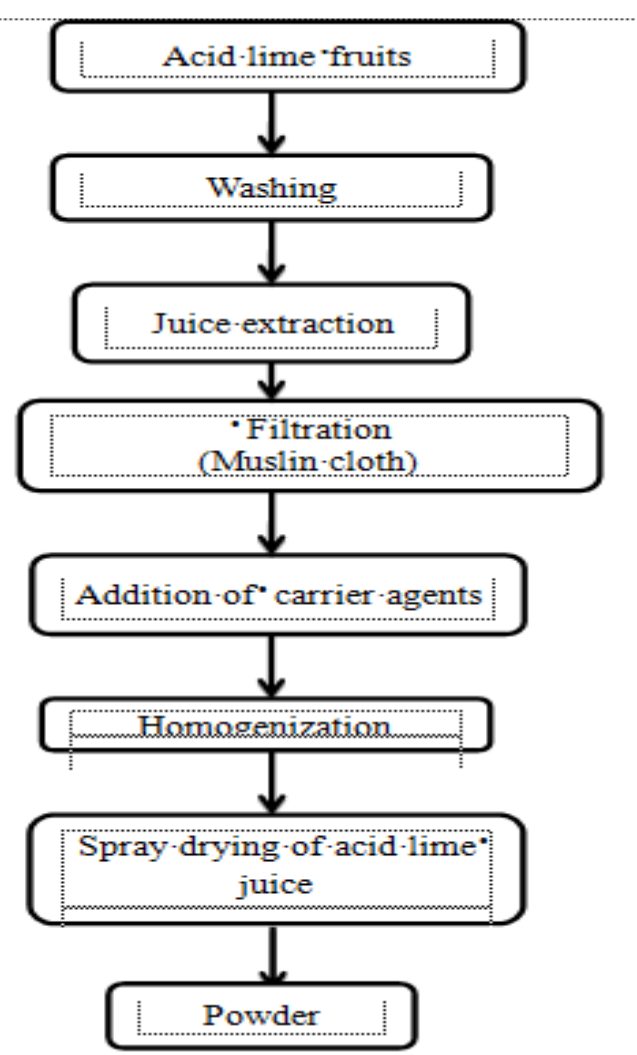

Figure 1: Flow Chart for Preparation of Acid Lime Juice Powder

\section{Experimental Setup}

Spray dried acid lime juice powder was produced using Labultima (model LU-222, Advanced) laboratory spray dryer. The spray dryer operates concurrently and has a spray nozzle, two-fluid atomizer with 0.7 mm diameter orifice. The inlet air temperatures of 140,150 and $160^{\circ} \mathrm{C}$ were used for all the solutions. The outlet air temperature was recorded at 10 min interval. The acid lime juice was fed into the drying chamber using a peristaltic pump. The liquid feed rate to the dryer was 5 per cent and the aspirator rate was 50 per cent. The atomization air pressure was set to $3 \mathrm{~kg} / \mathrm{cm}^{2}$ on the air pressure regulator. The testing was performed at constant process conditions. The product obtained was in aluminum laminated $(0.02 \mathrm{~mm})$ pouches. The pouches were then stored in a desiccators containing silica gel before quality evaluation. The physical properties of the powder measured where moisture content, bulk density, powder recovery and solubility.

\section{Statistical Analysis}

The experiments were carried out in triplicate and different mean values were analyzed by analysis of variance (ANOVA) and least significant difference (LSD) and Tukey's test ( $\mathrm{p}=0.05)$ was used to determine the difference between means and homogeneous subsets using statistical software SPSS 21.0 (SPSS Inc., USA). The graphs of mean values were created using Excel version 2003.

\section{RESULTS AND DISCUSSIONS}

\section{Effect of Spray Drying Process Parameters on Physico-Chemical Properties of Acid Lime Juice Powder}

Spray drying parameters were the most important factors which influence the physico-chemical properties of 
powders. The levels of independent variables selected for the present experimentations were 140,150 and $160^{\circ} \mathrm{C}$ inlet air temperature, $75,87.5$ and $100 \mathrm{~mL} / \mathrm{h}$ feed flow rate and 14, 16 and 18 per cent concentrations of carrier agents on the basis of preliminary trials conducted. The effect of these independent variables on the different properties such as moisture content, powder recovery, water solubility index and vitamin $\mathrm{C}$ content of acid lime juice powder was determined and mean of three replications were calculated.

\section{Moisture Content}

Moisture content is the most important property of spray dried powder which indicates the quality and shelf life of the product. Moisture content is related to the drying efficiency, powder flowability and storage stability of the powder (Mahdavi et al., 2016). The inlet air temperature, feed flow rate and concentration of carrier agents were usually the main parameters controlling the moisture content of the powder (Figure 1). The moisture content of the powder ranged between 2.404 to 5.739 per cent for all treatment of independent parameters. The moisture content of the powder prepared using maltodextrin, Arabic gum and blend of maltodextrin and gum Arabic was found to be 3.902, 3.317 and 3.598 per cent, respectively. Significant decreased in moisture content from 4.042 to 3.180 percent was observed to increase in the carrier agents concentrations from 14 to 18 per cent. Increasing the concentration of carrier agents during spray drying had resulted in decreasing the moisture content of acid lime juice powder, probably due to an increase in solids in the feed and reduced amount of free water. The increase in inlet air temperature resulted in significantly decreased in the percent moisture content of the acid lime juice powder. Fazaeli et al. (2012) observed the effect of different carrier agents (maltodextrin 6, 9 and $20 \mathrm{DE}$ and gum Arabic), inlet air temperature (110, 130 and $\left.150{ }^{\circ} \mathrm{C}\right)$ and concentration of carrier agents $(8,12$ and $16 \%)$ on the moisture content of the black mulberry juice powder. They observed that the increase in inlet air temperature and concentration of carrier agents decreased the moisture content of the powder. Mahdavi et al. (2016) observed the effect of different wall materials such as maltodextrin (MD) and blend of maltodextrin (MD) and Arabic gum (AG) on the moisture content of barberry powders. The higher moisture content in the powder produced by using maltodextrin as a carrier agent as compared to the blend of MD and AG was observed. Fazaeli et al. (2012) also observed that the moisture content of the powder was significantly reduced by increasing percent replacement of MD by gum Arabic. Increase in concentration of carrier agents, reduced the percent moisture content of the powder. The results might be due to the increased level of feed solids and reduced the level of total moisture for evaporation (Grabowski et al., 2006 and Kha et al., 2010). The feed flow rate was positively affected the moisture content in the Acai juice powder. Higher flow rates imply in a shorter contact time between the feed and drying air and making the heat transfer less

efficient, thus caused the lower water evaporation (Tonon et al., 2008). The findings of the present investigation were in accordance with the results obtained by Abadio et al. (2004) for pineapple juice powder, Goula et al. (2004) for tomato powder, Chegini and Ghobadian (2005) for orange juice powder, Rodriguez-Hernandez et al. (2005) for cactus pear juice powder, Ersus and Yurdagel (2007) for black carrot powder, Mahendran, (2010) for guava powder, Kha et al. (2010) for Gac juice powder, Zareifard et al. (2012) for lime juice powder and Mishra et al. (2014) for amla juice powder.

\section{Powder Recovery}

The effects of spray drying parameters on the recovery of the acid lime juice powder are presented in the Figure 2. The recovery of powder from acid lime juice varied from 11.987 to 20.945 per cent for all the treatment combinations. The results showed that the concentration of carrier agents had the significant effect, while inlet air temperature and feed flow rate showed non-significant effect on the powder recovery. Recovery of powder, prepared by using maltodextrin, Arabic 
gum and blends of maltodextrin and Arabic gum were found to be 16.359, 16.645 and 17.307 per cent, respectively. An increase in the concentration of carrier agents as 14, 16 and 18 percent, resulted increase in powder recovery as 14.367 , 16.760 and 19.185 per cent, respectively. Powder recovery was increased with increase in concentration of carrier agents, while decreasing with an increase in the feed flow rate (Figure 2). The non-significant effect of inlet air temperature on powder recovery was observed. Increase in inlet air temperature up to $150^{\circ} \mathrm{C}$, increases the powder recovery. Further increase in inlet air temperature reduces the powder recovery; this could be due to the fusion of existing carbohydrates, which increases the formation of deposits in the internal wall of drying chamber when maltodextrin was added as a carrier agent, whereas in the case of Arabic gum was due to the non-enzymatic browning of acid lime juice powder at higher temperature.

Carrier agents are necessary to produce powders from juices with high sugar and acid content, due to their low glass transition temperature (Chegini and Ghobadian, 2007 and Quek et al., 2007). MD has proven to be a very good encapsulant for low molecular weight sugars such as fructose and organic acids to increase the glass transition temperature (Adhikari et al., 2003 and 2004). Fazaeli et al. (2012) also observed that, among the different carrier agents, powder, prepared with MD 20 DE had a highest powder yield followed by MD 9 DE, Arabic gum and MD 6 DE, respectively. Chegini and Ghobadian (2007) and Horuz et al. (2012) observed the deceased in powder recovery to increase in inlet air temperature, this could be due to the fusion of existing carbohydrates, which increases the formation of deposits in the internal wall of drying chamber when maltodextrin was added as carrier agent. Whereas, in the case of Arabic gum decreased in recovery of powder with an increase of inlet air temperature, may be due to the non-enzymatic browning of the powder higher temperature (Avila et al., 2015). The higher feed flow rate showed a negative effect on process yield. The higher feed flow rate, resulting the decreased heat and mass transfer and the lower process yield. In addition, when higher feed rates were used, a dripping inside the main chamber was observed, when the mixture was passed straight to the chamber and that was not atomized and finally resulting the lower process yield (Toneli et al., 2006).

\section{Water Solubility Index}

The spray drying parameters viz., inlet air temperature, feed flow rate and concentration of carrier agents were the most important factors influencing the water solubility index of powder (Figure 3). Water solubility index of spray dried acid lime juice powder ranged from 91.960 to 98.080 per cent for all the treatments of process parameters. It was observed that, the water solubility index of powders prepared by using three different carrier agents' viz., maltodextrin, Arabic gum and blend of maltodextrin and Arabic gum were found to be $94.940,95.891$ and 95.347 per cent, respectively. Spray drying parameters viz., inlet air temperature $\left(140\right.$ to $\left.160^{\circ} \mathrm{C}\right)$, feed flow rate $(75$ to $100 \mathrm{ml} / \mathrm{h})$ and concentration of carrier agent $(14$ to $18 \%$ ) showed the significant effect on the water solubility index, whereas, interactions between the different parameters had the non-significant effect on the water solubility index of the acid lime juice powder. Lower the moisture content, higher the water solubility index of the powder was observed. Powder prepared by using Arabic gum as a carrier agent had lower moisture content as compared to maltodextrin and a blend of maltodextrin and Arabic gum, therefore water solubility index of the powder prepared using Arabic gum was found to be higher.

The water solubility index of the powder was found to be increased from 95.175 to 95.616 per cent and 93.376 to 96.724 per cent with an increase in inlet air temperature and concentration of carrier agents from 140 to $160^{\circ} \mathrm{C}$ and 14 to 18 percent, respectively, and decreased from 96.433 to 94.607 per cent with an increase in the feed flow rate from 75 to $100 \mathrm{ml} / \mathrm{h}$. The inlet air temperature and concentration of maltodextrin had a positive effect, whereas feed flow rate had a 
negative effect on the water solubility index of the acid lime juice powder. Caliskan and Nur Dirim (2013) and Nadeem et al. (2011) found that the increase in concentrations of carrier agents increased the solubility of the powder with types of carrier agents. According to Cano-Chauca et al. (2005), maltodextrin was mainly used in the process of spray drying due to its physical properties, such as high solubility in water. Grabowski et al. (2006) also reported that the water solubility index of sweet potato powder was increased as the amount of maltodextrin was increased. The maltodextrin was a powder with low moisture that exhibited good solubility and added no flavour and odour to the final product (Kenyon, 1995 and Wang and Wang, 2000).

Goula and Adamopoulos (2008a) and Nadeem et al. (2011) observed that increase in inlet air temperature lead to increase in the solubility of the tomato pulp powder and mountain tea powder, respectively which might be due to decreased moisture content. Also, powder produced at higher temperature and lower feed rate resulted in powders with higher solubility due to their negative effect on the moisture content of the powder sample Muzaffar and Kumar (2015). Maltodextrin was one of the most frequently used drying agent of plant extracts due to its high solubility in water. Similar results also reported by Cano-Chauca et al. (2005) for mango powder, Goula and Adamopoulos (2005) for roselle extracts and Yousefi et al. (2011) for pomegranate juice powder.

\section{Vitamin C}

Vitamin $\mathrm{C}$ is probably the most important water-soluble antioxidant as well as an efficient scavenger of reactive oxygen species and acid lime is a rich source of this nutrient (González-Molina et al., 2010). The content of vitamin C is an indicator of the quality of the juice and in the spray drying process; vitamin $\mathrm{C}$ plays an important role in assessing the degree of protection by carrier agents used. A significant difference was observed in the vitamin $\mathrm{C}$ content of the acid lime juice powder, prepared at different spray drying process parameters. The vitamin $\mathrm{C}$ content of acid lime juice powder varied between 250.995 to $387.155 \mathrm{mg} / 100 \mathrm{~g}$ powder. It was observed that the vitamin C content of the powder prepared using different carrier agents viz., maltodextrin, Arabic gum and blend of maltodextrin and Arabic gum recorded were $278.508,364.808$ and $326.843 \mathrm{mg} / 100 \mathrm{~g}$, respectively.

Among the different carrier agents, maltodextrin was found to be superior carrier agents which retained, the maximum vitamin $\mathrm{C}$ content followed by a blend of maltodextrin and Arabic gum and Arabic gum. A maximum vitamin $\mathrm{C}$ content of $368.584 \mathrm{mg} / 100 \mathrm{~g}$ of powder was observed in the MD concentration of 16 per cent, feed flow rate of $87.5 \mathrm{ml} / \mathrm{h}$ and inlet air temperature of $150{ }^{\circ} \mathrm{C}$ with the moisture content of 4.098 per cent, powder recovery of 16.893 per cent and water solubility index of 95.530. Maximum vitamin C content was retained in the powder prepared by using maltodextrin as a carrier agent followed by a blend of maltodextrin and Arabic gum and Arabic gum (Fig 4).

Chauhan et al. (2014) and Mahendran (2010) observed that, increase in the concentration of MD, the vitamin C content of guava powder decreased from 996 to $813 \mathrm{mg} / 100 \mathrm{~g}$ and 782.1 to $681.3 \mathrm{mg} / 100 \mathrm{~g}$, respectively. Vitamin C content was decreased with the increase of inlet air temperature. The degradation of vitamin $\mathrm{C}$ resulted from the disintegration of ascorbic acid at high air temperature (Lee et al., 2016 and schedule et al., 1983). With the increase in inlet air temperature, the rate of conversion of ascorbic acid to 2, 3-diketogulonic acid markedly increases, thereby reducing the vitamin $\mathrm{C}$ content (Gregory, 1996). The feed flow rate showed a positive effect on ascorbic acid content, might be due to the slower heat and the mass transfer occurring when the process was carried out with higher feed flow rates. Muzaffar et al. (2016) found that the combine effect of inlet air temperature, concentration of maltodextrin and feed flow rate on the vitamin $\mathrm{C}$ content of the powder. In the constant concentration of $\mathrm{MD}$, increase in inlet air temperature decreases the vitamin $\mathrm{C}$ 
content and increases with increase in feed flow rate. Quek et al. (2007) reported that the maltodextrin is the superior carrier agent for preparation of fruit juice powder as it retained, the maximum amount of micronutrient present in the food as compared to other carrier agents. Similar findings were reported by Muralikrishna et al. (1969) for guava puree, Abadio et al. (2004) for pineapple juice powder, Tonon et al. (2010) for Acai juice powder, Ferrari et al. (2013) for blackberry powder, Muzaffar and Kumar (2015) for pomegranate juice powder, Selvamuthukumaran and Khanum (2014) for Seabuckthorn fruit juice powder, Patil et al. (2014) and Chauhan et al. (2014) for guava powder, Muzaffar et al (2016) for pomegranate juice powder and Lee et al. (2016) for mandarin beverage.

\section{CONCLUSIONS}

Among the different carrier agents, maltodextrin was found to be superior carrier agents for preparation of acid lime juice powder based on the physico-chemical and sensory parameters.

The maximum vitamin $\mathrm{C}$ content was observed in the powder prepared using maltodextrin. The process parameters for retention of maximum vitamin C $(368.584 \mathrm{mg} / 100 \mathrm{~g})$ were inlet air temperature of $150^{\circ} \mathrm{C}$, concentration of maltodextrin of 16 percent and flow rate of $87.5 \mathrm{~mL} / \mathrm{h}$. RTS prepared from powder using maltodextrin obtained a maximum overall acceptability score $(8.60 \pm 0.17)$. At these process conditions, moisture content, powder recovery and water solubility index obtained were 4.098 per cent (d.b.), 16.893 per cent and 95.530 per cent, respectively.

\section{REFERENCES}

1. Abadio FDB, Domingues AM, Borges SV and Oliveira VM (2004). Physical properties of powdered pineapple (Ananas comosus) juice effect of maltodextrin concentration and atomization speed. Journal of Food Engineering, 64: 285-287.

2. Anonymous (2014). Citrus: lime and lemon, Indian Horticulture Database 2013, 46-53.

3. Avila EL, Rodríguez MC and Velásquez HJC (2015). Influence of maltodextrin and spray drying process condition on sugarcane juice powder quality. Revista Facultad Nacional de Agronomía - Medellín, 68(1): 7509-7520.

4. Cai YZ and Corke H (2000). Journal of Food Science, 65(6): 1248-1252.

5. Caliskan $G$ and Nur Dirim S (2013). The effects of the different drying conditions and the amounts of maltodextrin addition during spray drying of sumac extract. Food and Bioproducts processing, 91: 539-548.

6. Naveena B et.al., Effect of Calcium Chloride, Sodium Chloride and Lime Juice on Physico-Chemical Properties of Cucumber, International Journal of Agricultural Science and Research (IJASR), Volume 7, Issue 4, July - August 2017, pp. 765-770

7. Cano-Chauca M, Stringheta PC Ramos AM and Cal-Vidal J (2005). Effect of the carriers on the microstructure of mango powder obtained by spray drying and its functional characterization. Innovative Food Science and Emerging Technology, 6: 420-428.

8. Chegini GR and Ghobadian B (2007). Spray dryer parameters for fruit juice drying. World J. Agril. Sci. 3: 230-36.

9. Chegini RG and Ghobadian B (2005). Effect of spray-drying conditions on physical properties of orange juice powder. Drying Technology 23: 657-668.

10. Davoodi MG, Vijayanand P, Kulkarni SG and Ramana KVR (2007). Effect of different pre-treatments and dehydration methods on quality characteristics and storage stability of tomato powder. LWT - Food Science and Technology, 40(10):1832-1840.

11. Dhuique-Mayer C, Veyrat CC, Ollitrault P, Curk F and Amiot MJ (2005). Varietal and inter specific influence on 
micronutrient contents in citrus from the Mediterranean area. J. Agric. Food Chem., 53: 2140-2145.

12. Fahad Y, Al-Juhaimi and Kashif Ghafoor (2013). Bioactive Compounds, Antioxidant and Physico-Chemical Properties Of Juice From Acid lime, Mandarin And Orange Fruits Cultivated In Saudi Arabia. Pak. J. Bot., 45(4): 1193-1196.

13. González-Molina E, Domínguez-Perles R, Moreno DA and García-Viguera C (2010). Natural bioactive compounds of Citrus limon for food and health. Journal of Pharmaceutical and Biomedical Analysis, 51(2):327-345.

14. Goula AM and Adamopoulos KG (2008). Effect of maltodextrin addition during spray drying of tomato pulp in dehumidified air. II. Powder properties. Drying Technology, 26(6): 726-737.

15. Goula AM, Adamopoulos KG and Kazakis NA (2004). Influence of spray drying conditions on tomato powder properties. Drying Technology 22 (5), 1129-1151.

16. Goula MA and Adamopoulos GK (2010). A new technique for spray drying orange juice concentrate. Innovative Food Science and Emerging Technologies 11: 324-351.

17. Grabowski JA, Truong VD and Daubert CR (2006). Spray drying of amylase hydrolyzed sweet potato puree and physiochemical properties of powder. Journal of Food Science, 71(5): E209-E217.

18. Horuz E, Altan A and Maskan M (2012). Spray drying and process optimization of unclarified Pomegranate (Punica granatum) juice. Drying Technology, 30: 787- 789.

19. Jumah RY, Tashtoush B, Shaker RR and Zraiy AF (2000). Manufacturing parameters and quality characteristics of spray dried jameed. Drying Technology, 18 (4-5): 967-984.

20. Kenyon MM (1995). Modified starch, maltodextrin, and corn syrup solids as wall materials for food encapsulation. ACS Symposium Series, 590: 42-50.

21. Khan IA (2007). Citrus Genetics: UK-CAB International, Breeding and Biotechnology, 370.

22. Kiefer S, Weivel M, Smits J Juch M Tiedtke J and Herbst N. (2010). Citrus flavonoids with skin lightening effects - Safetyand efficacy studies. Int. J. Appl. Sci., 132: 46-54.

23. Kristina S, Malin C, Pontus L, Helena L and Kjell B (2002). The effect of process variable on the degradation and physical properties of spray dried insulin intended for inhalation. International Journal of Pharmaceutics, 233: 227-237.

24. Kwapinska M and Zbicinski I (2005). Prediction of final product properties after co-current spray drying. Drying Technology 23: $1653-1665$.

25. Ladaniya M. (2008). Academic Press; Goa, India, Citrus Fruit Biology. Technology and Evaluation, pp: 593.

26. Lv X, Zhao S Ning Z, Zeng H Shu Y and Tao O (2015). Citrus fruits as a treasure trove of active natural metabolites that potentially provide benefits for human health. Chem Cent J., 9: 68.

27. Mrkic V, Cocci E, Rosa MD and Sacchetti G (2006). Effect of drying conditions on bioactive compounds and antioxidant activity of broccoli (Brassica oleracea L.). Journal of the Science of Food and Agriculture, 86(10):1559-1566.

28. Murugesan R and Orsat V(2011). Spray drying of elderberry (Sabucus nigra L.) juice to maintain its phenolic content. Drying Technology, 29: 1729-1740.

29. Nadeem HS, Torun M and Ozdemir F (2011). Spray drying of the mountain tea (Sideritis strica) water extract by using different hydrocolloid carriers. LWT Food Science and Technology, 44: 1626-1635.

30. Narang $N$ and Jiraungkoorskul W (2016). Anticancer Activity of Key Lime, Citrus aurantifolia, Pharmacogn Review, 10(20): 118-122. 
31. Papadakis SE, Gardeli C and Tzia C (2006). Spray drying of raisin juice concentrates. Drying Technology, 24: 173-180.

32. Pellegrini N, Serafini M, Colombi B, Rio DD, Salvatore S and Bianchi M (2003). Total antioxidant capacity of plant foods, beverages and oils consumed in Italy assessed by three different in vitro assays. J. Nutr., 133: 2812-2819.

33. Peterson JJ, Beecher GR, Bhagwat SA, Dwyer JT, Gebhardt SE and Haytowitz DB (2006). Flavanones in grapefruit, acid limes, and limes: A compilation and review of the data from the analytical literature. J. Food Compos. Anal., 19: S74-S80.

34. Rufián-Henares JA, García-Villanova B and Guerra-Hernández E (2008). Occurrence of furosine and hydroxymethylfurfural as markers of thermal damage in dehydrated vegetables. European Food Research and Technology. 228(2): $249-256$.

35. Sagar VR and Suresh Kumar P (2010). Recent advances in drying and dehydration of fruits and vegetables: a review. Journal of Food Science and Technology 47: 15-26.

36. Sharifi A, Niakousari M, Maskooki A and Mortazavi SA (2015). Effect of spray drying conditions on the physicochemical properties of barberry (Berberis vulgaris) extract powder. International Food Research Journal, 22(6): 2364-2370.

37. Shrestha AK, Ua-arak T, Adhikari BR, Howes $T$ and Bhandari BR (2007). Glass transition behavior of spray dried orange juice powder measures by differential scanning calorimetry (DSC) and thermal mechanical compression test (TMCT). International Journal of Food Properties, 10: 661-673.

38. Sousa AS, Borges SV, Magalhaes NF, Ricardo HV and Azavedo AD (2008). Spray dried tomato powder: Reconstitution properties and color. Brazilian Archives of Biology and Technology, 51: 807-817.

39. Toneli J, Park KJ, Murr F and Negreiros A (2006). Spray drying optimization to obtain inulin powder. In Proceedings of the 15th International Drying Symposium, Budapest, Hungary.

40. Tonon VR, Brabet $C$ and Hubinger DM (2008). Influence of process conditions on the physicochemical properties of acai (EuterpeOleraceae Mart.) powder produced by spray drying. Journal of Food Engineering, 88: 411-418.

41. Truong V, Bhandari BR and Howes $T$ (2005). Optimization of concurrent spray drying process of sugar-rich foods. Part IMoisture and glass transition temperature profile during drying. Journal of Food Engineering, 71(1): 55-65.

42. Walton DE and Mumford CJ (1999). Spray dried products-characterization of particle morphology. Chemical Engineering Research and Design 77 (1), 21-38.

43. Wang YJ and Wang L (2000). Structures and properties of commercial maltodextrins from corn, potato, and rice starches. Starch-Stärke, 52(8-9): 296-304.

44. Yousefi S, Emam-Djomeh Z and Mousavi MS (2011). Effect of carrier type and spray drying on the physicochemical properties of powdered and reconstituted pomegranate juice (Punica Granatum L.). Journal of Food Science and Technology 48: 677684. 


\section{APPENDICES}

Figures:
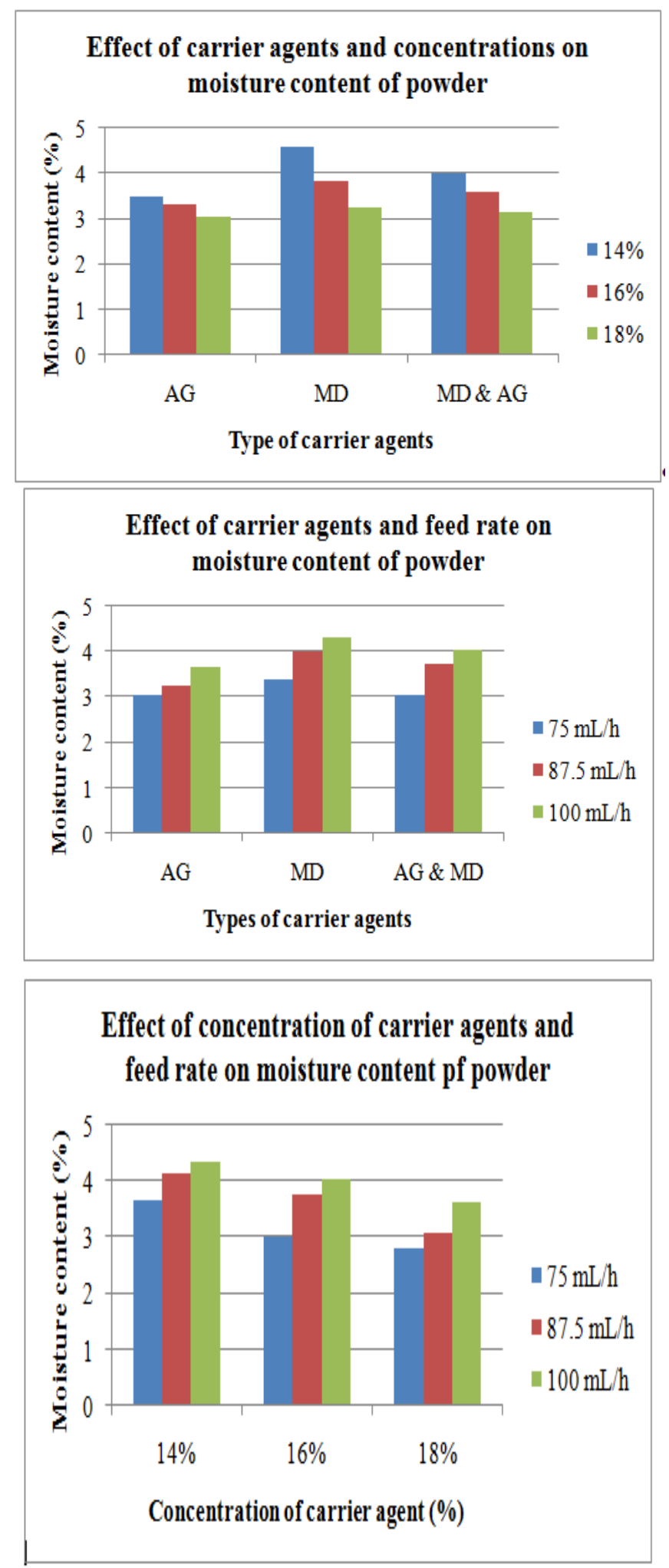


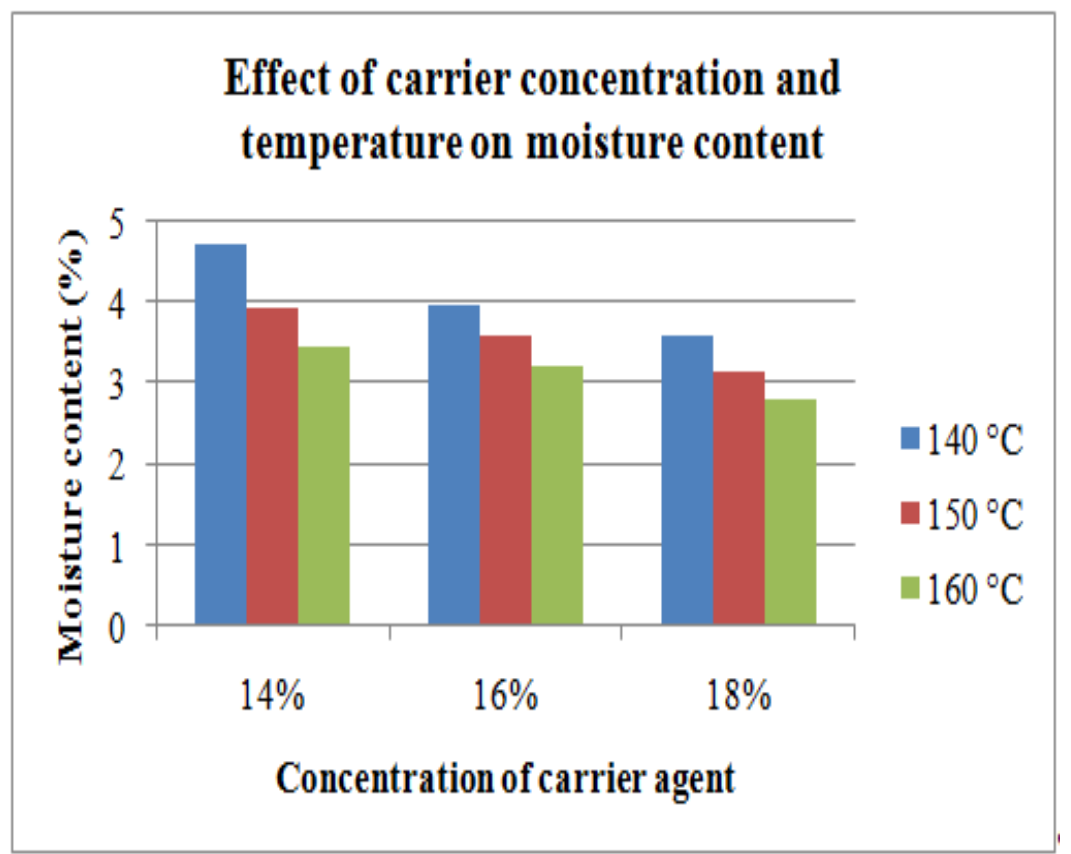

Figure 2: Effect of Spray Drying Parameters on Moisture Content of Lime Juice Powder

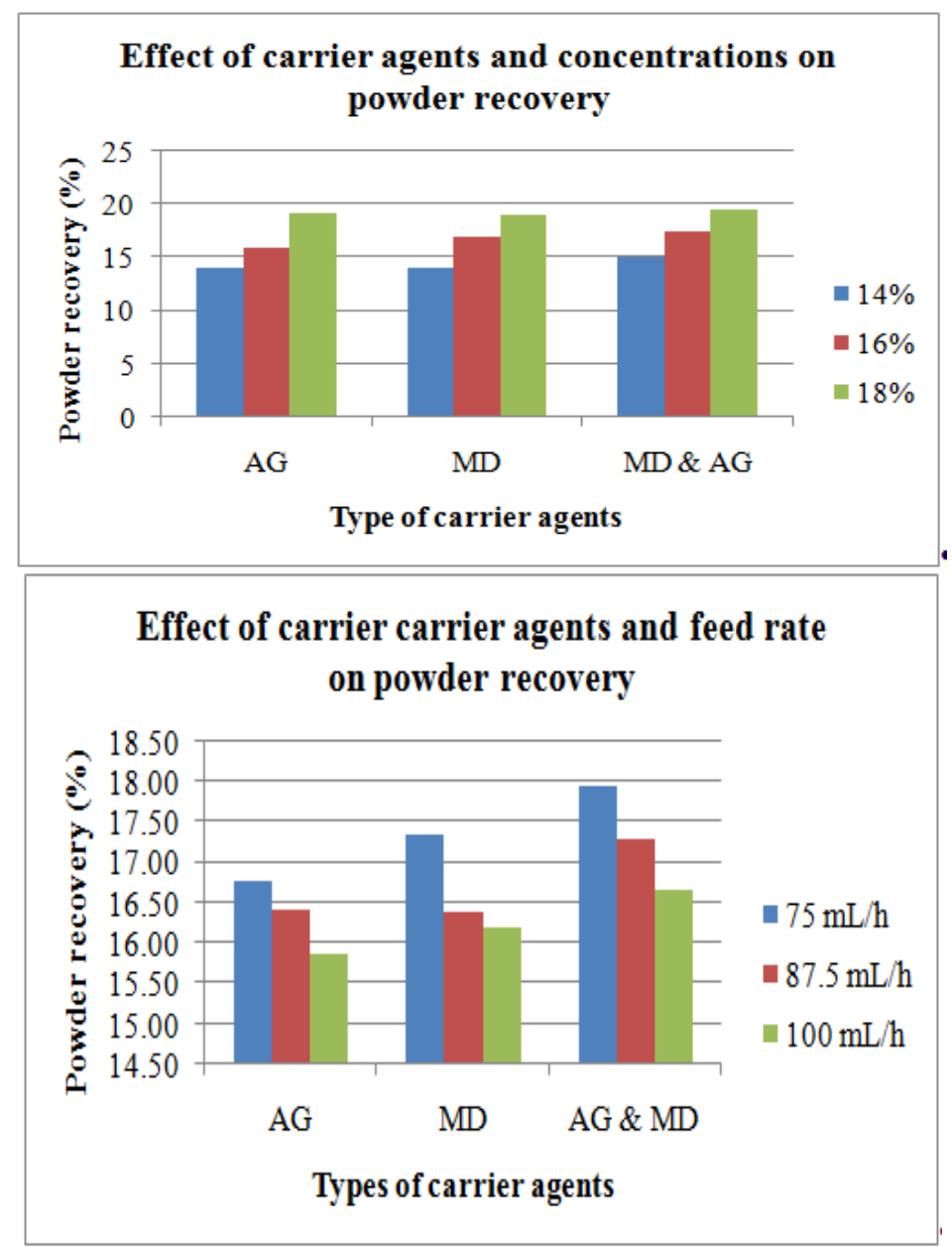




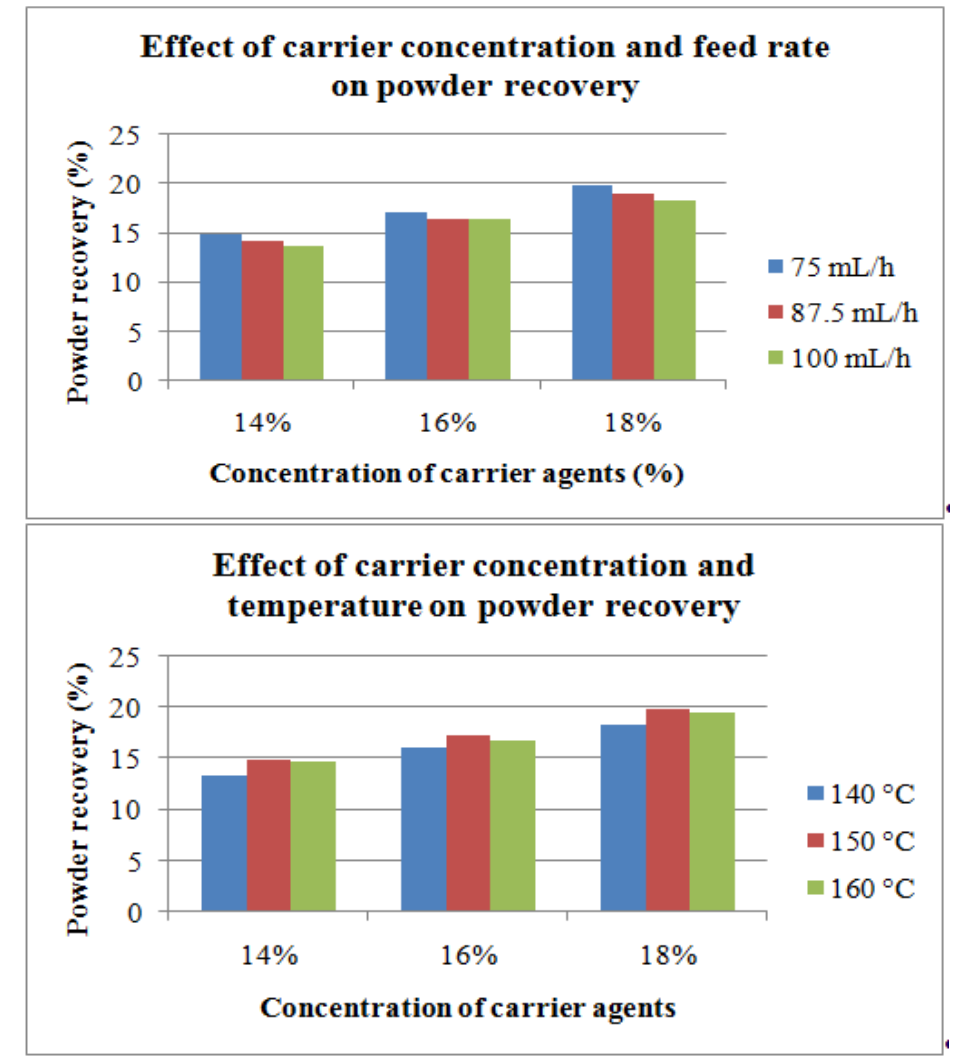

Figure 3: Effect of Spray Drying Parameters on Recovery of Lime Juice Powder

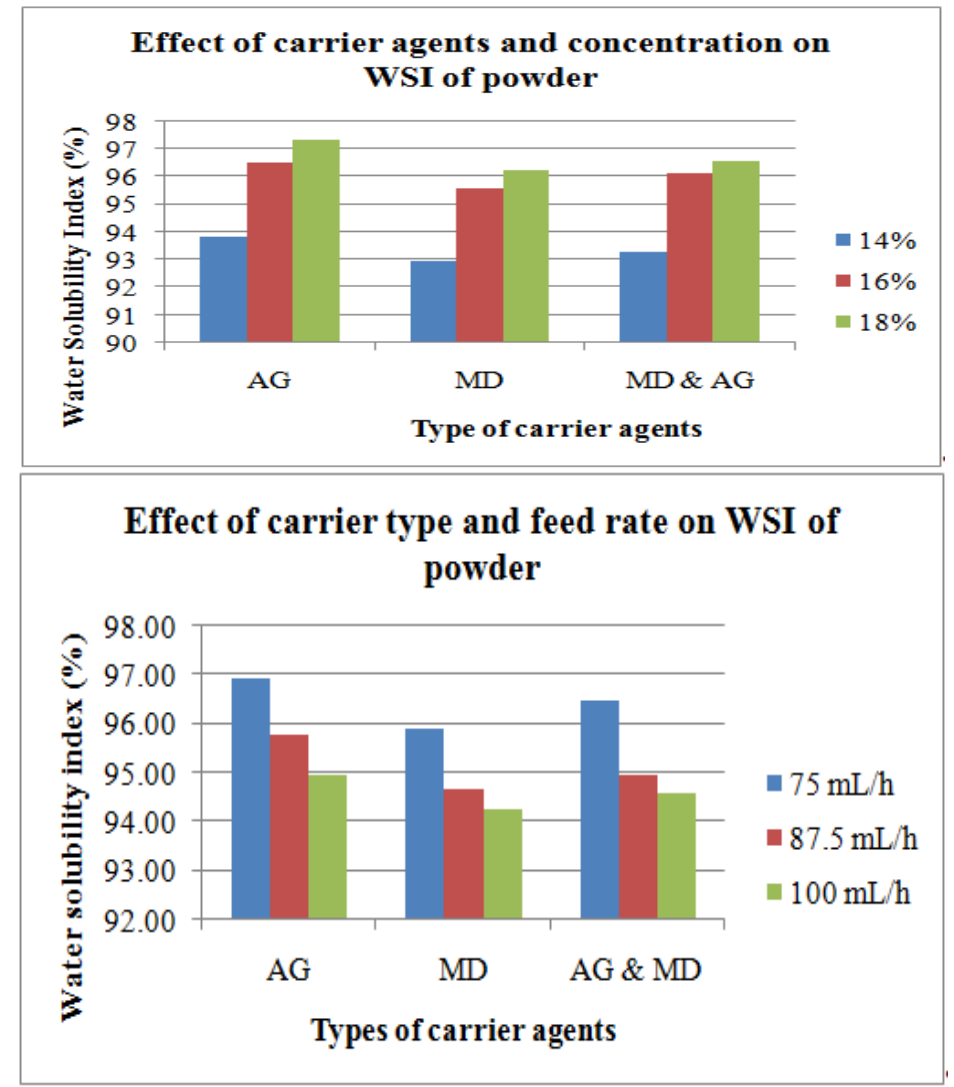




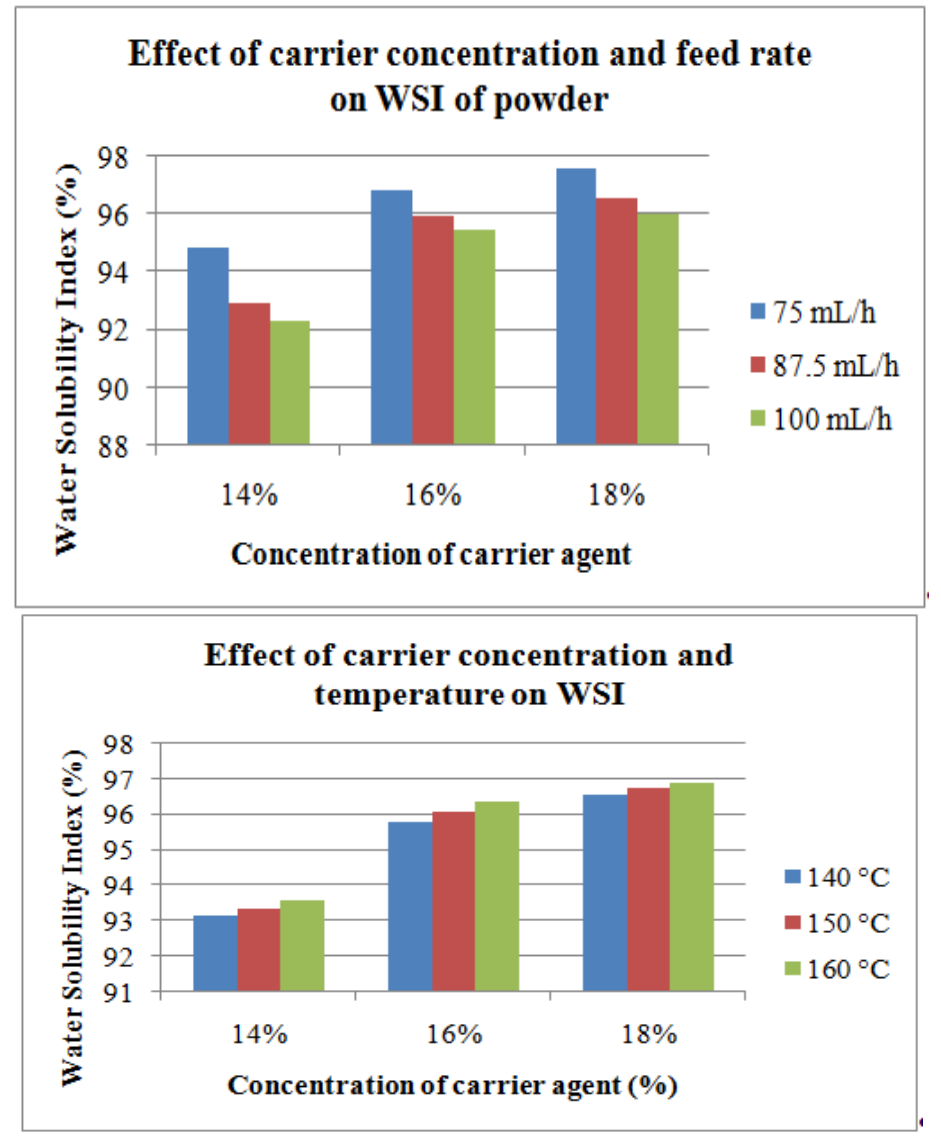

Figure 4: Effect of Spray Drying Parameters on Water Solubility Index of Lime Juice Powder

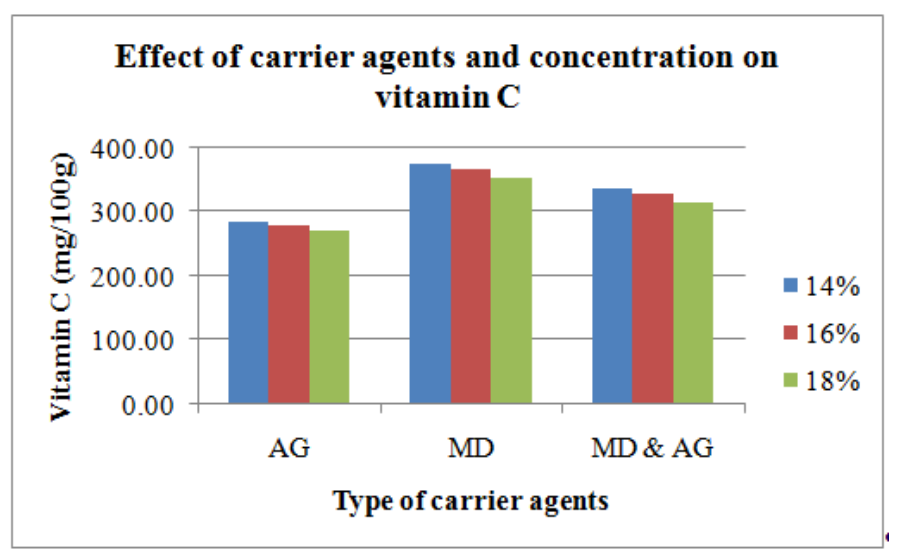




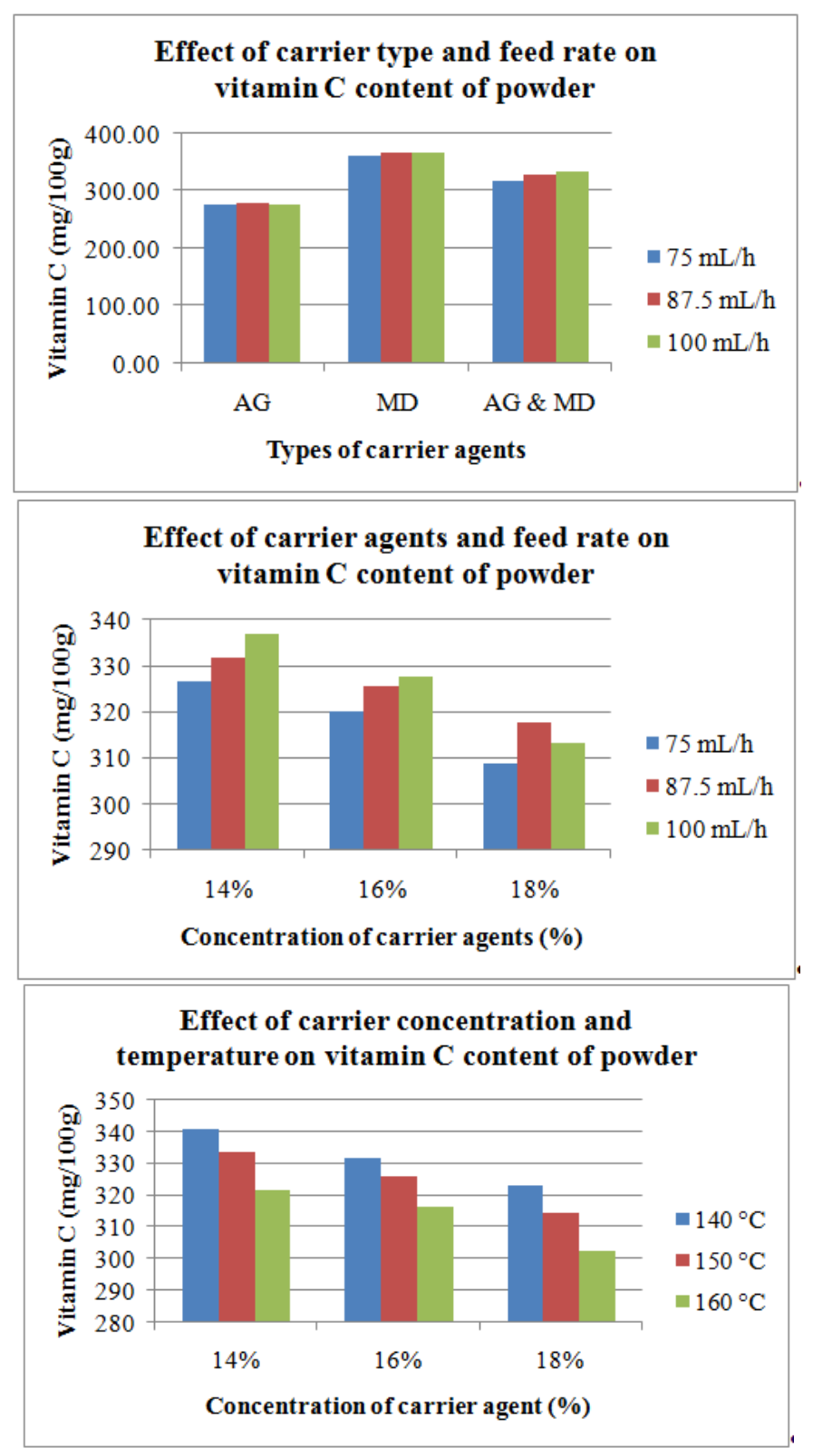

Figure 5: Effect of Spray Drying Parameters on Vitamin C Content of Lime Juice Powder 